\title{
Citizen Science and Citizens' Observatories: Trends, Roles, Challenges and Development Needs for Science and Environmental Governance
}

\author{
Hai-Ying Liu, Sonja Grossberndt and Mike Kobernus \\ NILU-Norwegian Institute for Air Research, Kjeller 2027, Norway \\ Email address for corresponding author: hai-ying.liu@nilu.no
}

\begin{abstract}
This chapter explores growing and important trends within citizen sensing, especially those linked to major initiatives that form citizens' observatories and address novel ways to engage citizens in science and environmental policymaking. On the basis of providing an overview of existing and planned citizen science and citizens' observatories programmes, this chapter identifies areas where citizen science and citizens' observatories have actively contributed to, and can be expected to see further development in, the formation of various policies in Europe. Furthermore, this chapter considers the motivations for developing citizen science and citizens' observatories and how these initiatives can contribute to awareness raising and decision support systems. We address key challenges and development needs for policy- and decision-making within the context of widespread and accessible citizen science and of the activities of citizen observatories.
\end{abstract}

How to cite this book chapter:

Liu, H-Y, Grossberndt, S and Kobernus, M. 2017. Citizen Science and Citizens'

Observatories: Trends, Roles, Challenges and Development Needs for Science and Environmental Governance. In: Foody, G, See, L, Fritz, S, Mooney, P, OlteanuRaimond, A-M, Fonte, C C and Antoniou, V. (eds.) Mapping and the Citizen Sensor. Pp. 351-376. London: Ubiquity Press. DOI: https://doi.org/10.5334/bbf.o. License: CC-BY 4.0 


\section{Keywords}

Awareness raising; Citizens' observatories; Citizen science; Decision support systems; Environmental policy-making

\section{Citizen Science and Citizens' Observatories: A Growing and Important Trend to Engage Citizens in Science and Environmental Policy-making}

The participation of citizens in environmental monitoring and related scientific activities has a long tradition, dating back at least two centuries (Silvertown, 2009; UWE, 2013). The present digital era facilitates people's easy access to advanced Information and Communication Technology (ICT) systems (e.g., social media platforms, mobile Internet, online gaming or smartphone apps, etc.), enabling the public to participate in (scientific) projects on issues relevant to their local environment and to easily access data and information about the state of those data. The collaborative power of these advanced ICT systems is enormous, and can leverage a collective intelligence that has the potential to change the way environmental policy-making and monitoring is performed, as well as more effectively raise citizens' awareness of environmental issues. Numerous collaborative and co-design approaches have been developed and tested during the last decades. In this chapter, we will focus on two methodologies that are well suited to be applied in the context of 'Mapping and the citizen sensor': Citizen Science (CS) and Citizens' Observatories (COs), which both have applicability in the acquisition of spatial data through Volunteered Geographic Information (VGI).

In this section, we first define our terms (CS and CO) and discuss how these methodologies have become increasingly vital within science and policy-making (Sections 1.1 and 1.2). We then distinguish between CS and COs in general, and also especially in relation to major CS and CO initiatives that engage citizens in science and environmental policy-making.

\subsection{Citizen Science: old wine in new bottles}

Before diving directly into the world of CS, let us first review its definition. Generally, the term describes the activities of non-scientist citizens that contribute to scientific research. In the Oxford dictionary, we find the following definition: 'scientific work undertaken by members of the general public, often in collaboration with or under the direction of professional scientists and scientific institutions' (OED, 2014). CS approaches are also described as Public Participation in Scientific Research (PPSR). PPSR describes all efforts of lay people directed towards their involvement into scientific research activities (Shirk et al., 2012); 
it includes CS, but augments it with a broader definition of participation, not only limited to collecting scientifically relevant data. However, these definitions do not provide any information on the extent to which citizens are involved in the scientific work, whether they are only collecting data or whether they also participate in the creation of the study. Based on relevant literature, we have created an overview of the most prominent categories of public participation in scientific research (Figure 1, adapted from Bonney et al., 2009) and visualised a range of popular terms that are used in this context in a cloud tag (Figure 2).

Why do we need CS? CS offers many advantages. Due to restricted time and limited monetary resources, scientists cannot always collect large amounts of data or cover big geographic areas for both data collection and documentation (Dickinson et al., 2010; Tulloch et al., 2013). For this reason, the help of volunteers in collecting data can be extremely valuable. For example, since the US Weather Service did not have enough resources to set up a countrywide meteorological measuring network, they made use of volunteers all over the country to help in the data collection. The resultant data were one of the most important long-term datasets in the history of North America and have been used for essential work within climate research, agriculture and development planning

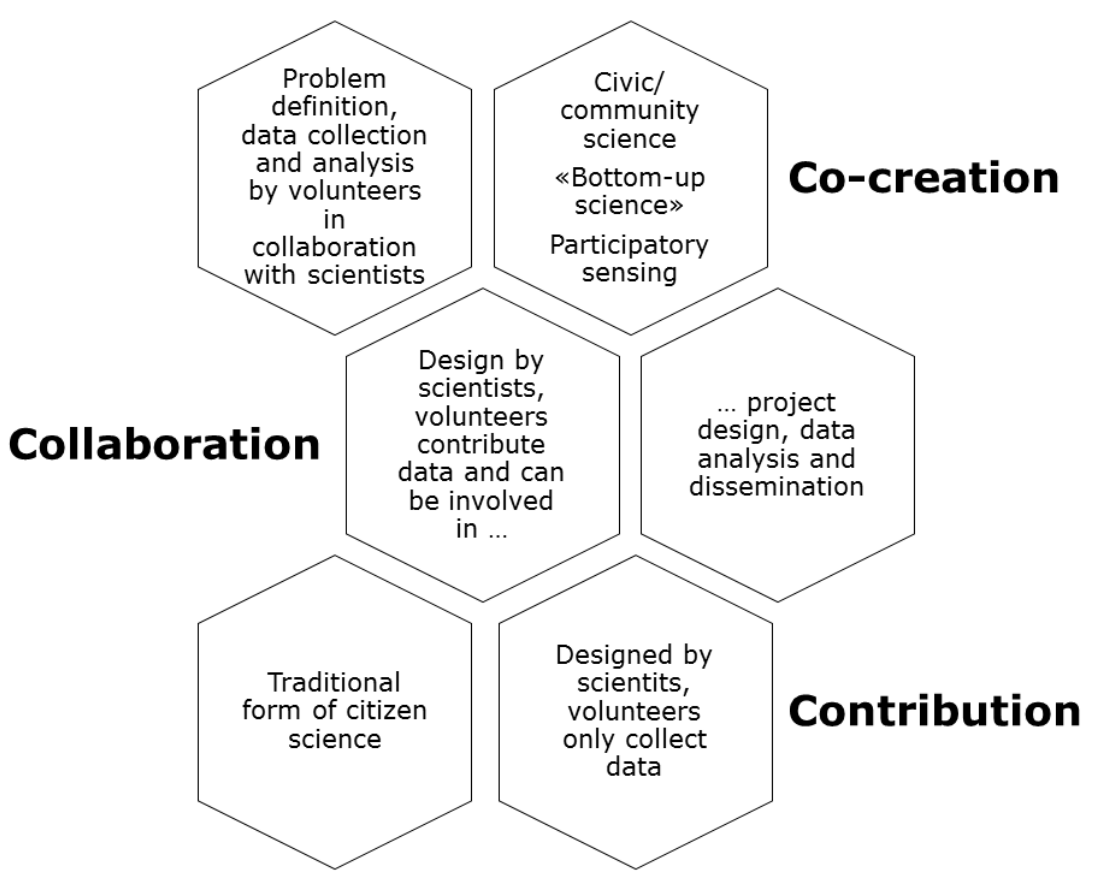

Fig. 1: Categories of citizen science. Modified from Grossberndt and Liu (2016). 'All rights reserved (c) Springer International Publishing Switzerland 2016'. 


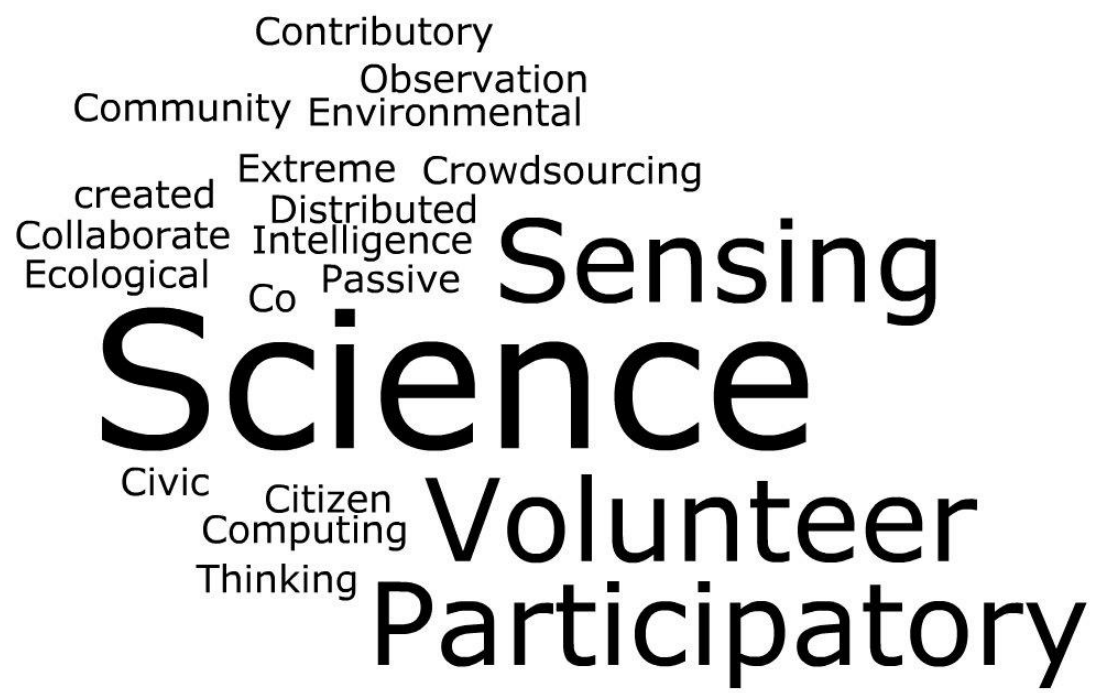

Fig. 2: Cloud tag visualising terms related to citizen science.

(Vetter, 2011). This example shows that the collection of data over many decades has led to the compilation of long-term data series, which are extremely valuable for the work of modern science (Miller-Rushing et al., 2012).

Another reason for the application of CS and other participatory approaches is to increase citizens' awareness of problems related to their immediate environment. In some cases, the activities can also result in greater interest and increased engagement in these issues. Engaging citizens can also have educational effects and increase science literacy (Haklay, 2015).

One would think that CS was a rather novel invention, considering that many scientists prefer to keep to themselves in their ivory towers and the concept of public participation is only gradually making its way into their thinking. Surprisingly enough, the roots of CS can be traced at least as far back as the 18th century. At this time, a Norwegian bishop engaged a large number of clergymen throughout the whole country and assigned them with the task of collecting observations and natural objects from all over Norway in order to assist him in his research (Brenna, 2011). Throughout the centuries, non-scientists/ laypeople have often been engaged in assisting scientists in the collection of data. Another more recent example is the traditional Christmas Bird Count in the USA, Canada and other Western countries that began in 1900: in the 2014/15 season, more than 72,000 volunteers participated in that programme (LeBaron, 2015).

Nowadays, a large number of CS activities have been initiated and are still ongoing, covering many different fields (see Section 2.2). The list of CS programmes is endless, and, during the last decades, CS activities have sprung 
up like mushrooms all around the globe. What has caused this phenomenon? There are several reasons. First and foremost, there have been rapid changes within ICT; for example, easy Internet access, the emergence of Web 2.0 systems and the rise of social media have enabled increased engagement with the public. Another aspect is the improvement and simplification of the collection, management and storage of data. More and more people have access to easy-touse devices like smartphones and other mobile devices with GPS positioning technology; this facilitates the involvement and connection of citizens around the world. Collecting data or taking a picture and sending it to a data server with the exact time and geographic position now takes split seconds, not hours or days. A second important reason for the emergence of CS initiatives is the changes in society. At least in Western countries, the level of education amongst the public has been increasing. More leisure time and a growing understanding of scientific concepts, as well as increased technical skills, even for the youngest in society, are contributing factors to CS initiatives. Thirdly, scientists have become more aware of the fact that citizen participation in the collection of scientific data can also be beneficial, due to resource limitations, as mentioned above. Recent study results indicate that savings in labour cost per project can reach up to US $\$ 200,000$ over the project's first 180 days, depending on the project (Sauermann and Franzoni, 2015).

\subsection{Citizens' Observatories: A New Concept}

As early as the 1970s, P.K. Feyerabend suggested that it was time for a democratisation of science; he claimed that 'everywhere science is enriched by unscientific methods and unscientific results' (Feyerabend, 1970). Essentially, he believed that the monopolisation of research by universities, corporations and other large institutions was contrary to the best interest of science, which, as we have seen, has a long history of public participation. However, in spite of his attempts to redress the lack of citizens or non-scientists within research, amateur participation was declining. This deficit was eventually recognised, and, in order to promote a more active participation from the public, the EU first commissioned the SOCIENTIZE project (2012-2014), to create a common forum for cooperation between e-Infrastructure providers and CS infrastructure providers, including any end user with an interest in contributing to the scientific process (Socientize, 2012-2014). The project produced the Green Paper on Citizen Science, which helped to create a 'roadmap' for CS in Europe. This led to a series of further initiatives where CS was incorporated in some form, especially within the development of the new concept of the CO (see Section 2.1).

The term CO was first addressed in the EU FP7 Topic ENV.2012.6.5-1: 'Developing community-based environmental monitoring and information systems using innovative and novel earth observation applications' (EC, 2014). 
It is a term that is applied to a framework that combines participatory community monitoring with monitoring by policy-makers, scientists and other stakeholders. Typically, this is achieved via a technological system that may include web portals, mobile technologies and sensors (Liu et al., 2014). The term was further developed within five projects that were funded within the EU FP7 Topic ENV.2012.6.5-1 (see Section 2.1). For example, in the CITI-SENSE project, a CO for supporting community-based environmental governance has been defined as 'the citizens' own observations and understanding of environmentally related problems and in particular as reporting and commenting on them within a dedicated ICT platform' (Liu et al., 2014) and was tested in nine cities in the field of air quality. In the WeSenseIt project, Ciravegna et al. (2013) defined a CO as 'a method, an environment and an infrastructure supporting an information ecosystem for communities and citizens, as well as emergency operators and policymakers, for discussion, monitoring and intervention on situations, places and events.' The CO in the WeSenseIt project is therefore seen as an environment for implementing collaboration, as infrastructure to validate the CO concept and as a method to demonstrate the applicability of its outcome (Lanfranchi et al., 2013).

There is no doubt that the term CO has become popular in CS programmes (especially EU-funded ones), and many new CO-related initiatives have been created at different levels. Accordingly, this new term represents a growing and important trend in both science and policy-making.

In practice, all $\mathrm{CO}$ projects typically share a similar model, including the main aspects needed to develop COs as a method for data collection. These include engaging the participation of citizens in data collection, data interpretation and information delivery. Alternatively, the CO model (Figure 3) combines (i) sequential aspects, (ii) interaction with citizens and other stakeholders, (iii) data collection tools, and (iv) an ICT infrastructure that underlies the CO framework and supports effective citizen participation.

A set of sequential aspects (the pyramid within Figure 3) has been identified by Liu et al. (2014) as follows: A) identifying what citizens want and what citizens can offer; B) exploring what products and services a $\mathrm{CO}$ can provide for the citizens; C) recruiting and retaining citizens to participate in and contribute to environmental governance; D) providing tools that support citizens to report their observations, inferences and concerns; and E) supplying tools to access/receive information on the environment in a manner that is both easily understood and useful, for citizens and other stakeholders, including policymakers.

The essential aspects of the interaction with citizens and other stakeholders (who are represented by the five circles along the bottom outer open edge in Figure 3) have been addressed in all existing CO models. A CO includes observations from not just professionals and scientists, but also citizens. An effective $\mathrm{CO}$ shall enable a two-way communication between citizens 


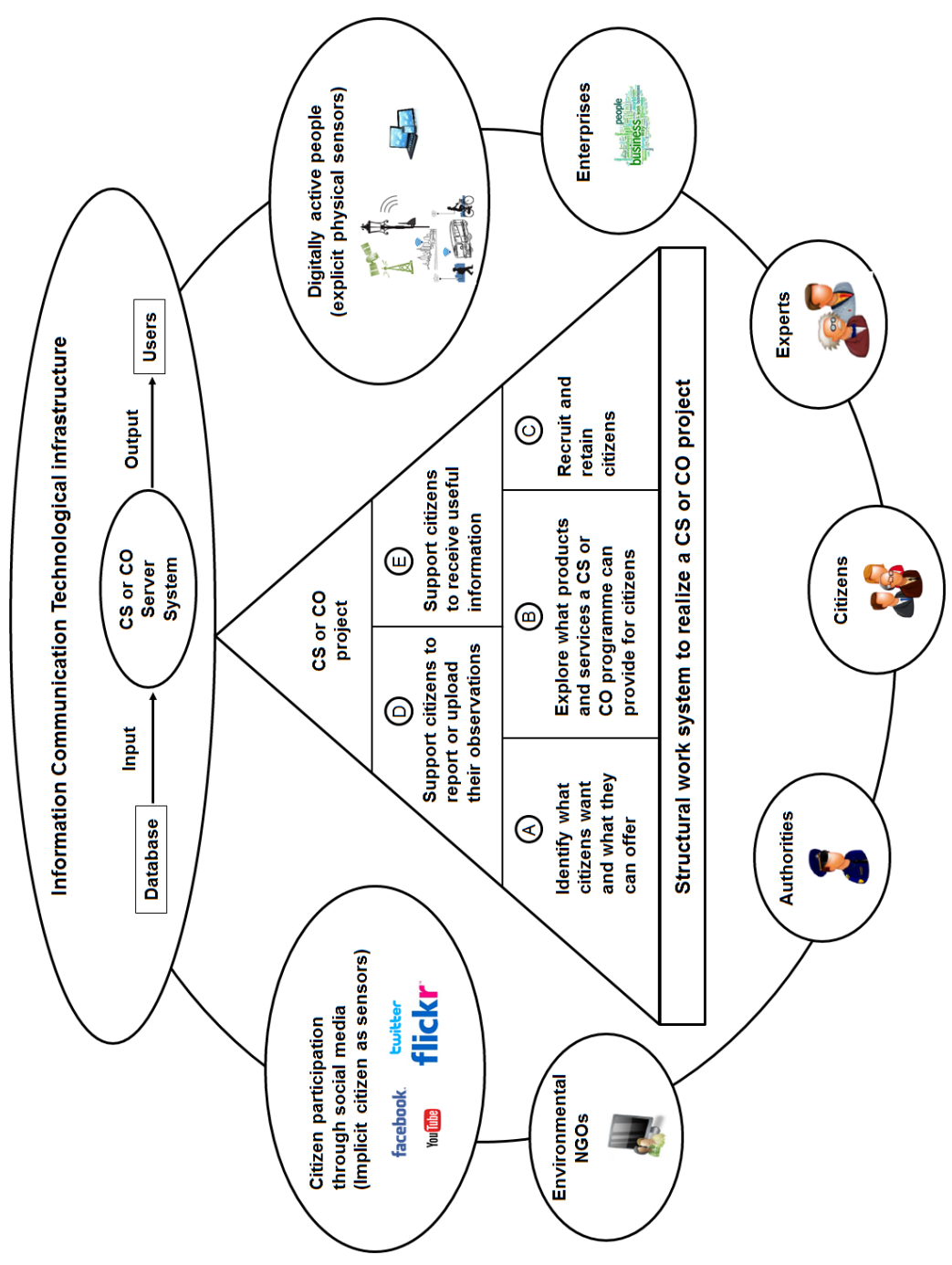

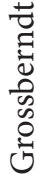

둥

웅

귱

$\sum$ 贾

氙

过

苋.

$\Xi$.

$\stackrel{0}{\exists}$

ีㅗㄹ

एँ.

늘

过

혼

岂

की

क (1)

:

○ั

莺

灵

단

ํํㅇ

$\varangle$.

ம்

幽 
and other stakeholders, potentially resulting in profound changes to local environmental management processes, and, as such, shall engage in social innovation processes and outcomes (Wehn and Evers, 2015). For example, the WeSenseIt project used social media and co-design approaches, exploring citizens' needs and providing a framework in which authorities and citizens cooperate in sharing collective intelligence and participate in planning, decision-making and governance regarding the water environment, including flood risk (WeSenseIt, 2012-2016).

The data collection tools (the two ovals along the outer open edge of Figure 3) are highlighted in the existing CO models as well. For example, the CITI-SENSE project engages citizens to use low-cost micro-sensors to monitor air quality in their surroundings (hard layer of data collection), and interacted with citizens via various social media and mobile apps (soft layer of data collection; CITI-SENSE, 2012-2016).

The ICT infrastructure (the large oval at the top of Figure 3 ) is an essential part of the CO model that includes boundary services with sensors and apps, data management services, data storage support and the reusable visualisation widgets used for both apps and web portals. Currently, existing CO projects are building all required ICT infrastructure towards a systematic, simple and reusable method to facilitate the setting up of new COs in various environmental fields, a method which can be applied by communities and organisations to overcome their challenges regarding the specific technical ICT skills and programming knowledge needed to create the necessary server infrastructure and mobile applications (Zaman et al., 2014).

\subsection{Citizen Science and Citizens' Observatories - Commonalities and Differences}

As mentioned previously, CS is a novel take on an old approach and is generally described as 'public participation in scientific research. COs are a new concept that evolved from EU policy circles, defining the combination of participatory community monitoring, technology and governance structures that are needed to monitor, observe and manage an environmental issue (Haklay, 2015).

Both CS and COs involve citizens in scientific research or various monitoring programmes, help citizens to play an active role in the data collection process and enable them to exchange data/information and knowledge, to reach the expert who can answer questions about various issues that are being addressed, and to disseminate information to further the understanding of such issues. The Chinese proverb 'Tell me and I'll forget; show me and I may remember; involve me and I'll understand' is an apt quotation in this context, since both CS and COs have great potential to be a suitable instrument to raise awareness, increase citizen participation and support community-based environmental decision-making. 
Whereas CO approaches focus very much on a two-way communication between citizens and other stakeholders, such as scientists, this may not always be the case for CS: here, the degree of participation can vary from only collecting data to participating in the study design and data analysis. In addition, CS usually refers to science/scientific projects, whereas COs include a broad range of stakeholders, including authorities or policy-makers. However, the combination of both top-down and bottom-up approaches makes COs a more complex tool, especially as they require an ICT infrastructure, which is not necessarily required for CS initiatives.

\section{Current Citizen Science and Citizens' Observatory Programmes in Europe}

\subsection{Citizens' Observatory Projects}

In recent years, there have been many ongoing COs projects in Europe. For example, the European Commission (EC) has seen the possibility of empowering European citizens in environmental monitoring, with the consequent increase in observational possibilities. The EC has provided funding through their Seventh Framework Programme for five projects (i.e., Citclops, CITI-SENSE, COBWEB, OMNISCIENTIS and WeSenseIt) with the aim of building COs in the various environmental fields. For example, OMNISCIENTIS has combined the active participation of citizens with the implementation of innovative technologies for improving the governance of odour nuisance (OMNISCIENTIS, 2012-2014). Other projects that emphasise the need for citizens' participation are COBWEB, which aimed at creating a test-bed environment that would enable citizens living within Biosphere Reserves to collect environmental data using mobile devices (COBWEB, 2012-2016; Higgins et al., 2016); Citclops, which aimed at developing an observatory based on CS applications for bio-optical monitoring of coast and ocean (Ceccaroni et al., 2016; Citclops, 2012-2015); and WeSenseIt, which puts emphasis on enabling citizens to become active stakeholders in information capturing, evaluation and communication for the marine environment, including flood risk (WeSenseIt, 2012-2016). Finally, CITI-SENSE aimed at empowering citizens to participate in environmental governance by developing various $\mathrm{CO}$ supporting services related to outdoor air quality, indoor air quality in schools and environmental perception in public spaces (CITI-SENSE, 2012-2016). These five CO projects were designed independently of each other; however, they had considerable similarities in terms of their structure, operation and methodology for communication with the public (Liu et al., 2014). Furthermore, there has been cross-project collaboration amongst these five projects to (i) facilitate data, knowledge and success sharing amongst the projects, and (ii) establish common methodologies and standards for crowdsourcing/ citizen science within GEOSS and aligned with INSPIRE and Copernicus ${ }^{1}$. 
In addition, four projects have been funded under the EC H2020 topic SC5-17-2015, 'Demonstrating the concept of "Citizen Observatories" (EC, 2015-2016), that aim to scale up, demonstrate, deploy, test and validate, under real-world conditions, the concept of $\mathrm{CO}$ and the effective transfer of environmental knowledge for policy, industrial, research and societal use, with a focus on the domain of land cover/land use, both in rural and urban areas. The EC H2020 topic CSA-2017 ('Coordination of Citizens' Observatories initiatives'; EC, 2016-2017b) aims at bringing existing CO and related communities together, and also the EC H2020 topic RIA-2017 ('Novel in-situ observation systems') will further develop ICTs and test them in various CO activities (EC, 2016-2017a).

Furthermore, with an increasing number of CO-based initiatives, the EU H2020 Work Programme 2016-2017 (Topic in SC5-19-2017) issued a call for the coordination of citizens' observatories initiatives (EC, 2016-2017b) to create a CO knowledge base in Europe across disciplines in order to avoid duplication, ensure interoperability, create synergies and facilitate the gradual uptake of this knowledge base by environmental authorities.

There are more existing and planned CO-related activities supported by the EC programmes and calls, for example:

- CAPS - Collective Awareness Platforms for Sustainability and Social Innovation (ICT Calls; 34 existing projects (EC, 2016));

- The new calls in 2016-2017 (EC, 2016-2017c) and Pilots and Coordination and Support Actions;

- Integrating Society in Science and Innovation (RRI) (EC, 2017);

- MYGEOSS (EC, 2015); and

- RIA - Novel in-situ observation systems (EC, 2016-2017a), etc.

\subsection{Citizen Science Projects}

In recent years, there has been a boom in CS projects, with many now harnessing new technologies, such as mobile Internet and smartphone apps, to increase accessibility and remote participation. For example, more than 1,600 formal and informal research projects, tools and events are listed on SciStarter and the number is increasing rapidly (SciStarter 2017). Some of the best known projects were and are run by the previous Zooniverse team, now Citizen Science Alliance, which launched the Galaxy Zoo galaxy-classifying project in 2007 (Zooniverse, 2013), and whose crowdsourcing model has been adopted by many other groups. However, there are many more examples of CS projects, which include, but are certainly not limited to, topics such as biological monitoring (e.g., the Cornell Lab of Ornithology, www.birds.cornell.edu; the Great Backyard Bird Count ${ }^{2}$; the big butterfly count ${ }^{3}$,), geography (e.g., OpenStreetMap ${ }^{4}$ ), air quality (e.g., Air Quality Egg ${ }^{5}$ ), and others that encom- 
pass different models of CS; within the environmental sciences, these span a diverse range of subjects.

The CS activities can differ in focus, approach or technique. Various reviews indicate that the most prominent topics for CS are biology, conservation and ecology, with citizens assisting in the collection and classification of data (Kviner, 2012; Science Communication Unit, University of the West of England, 2013; Liu et al., 2014; Grossberndt and Liu, 2016). Another main cluster is geographic information research, with citizens collecting geographic data; as the third most prominent group of CS topics, the study identified research involving the public in relation to environmental and health issues (Kullenberg and Kasperowski, 2016). There are also 'higher level' initiatives, like the Open Air Laboratories (OPAL) for CS initiatives focused on nature ${ }^{6}$, Geo-Wiki for projects addressing global land cover issues ${ }^{7}$ or Zooniverse, serving as a hub for projects from different fields ${ }^{8}$.

In Europe, CS has grown in scale and scope, and is therefore receiving increasing attention from scientists and policy-makers at local, national and international levels. Some of the well known European CS projects are ENERGIC $^{9}$, EmoMap $^{10}$ and EveryAware ${ }^{11}$. Gradually, CS has been considered as an independent discipline. For example, there are academic groups and collaborations (Science Communication Unit, University of the West of England, 2013), including the Citizen Cyberlab ${ }^{12}$, a Swiss partnership involving CERN, the UN Institute for Training and Research and the University of Geneva; and $\mathrm{OPAL}^{13}$;). Furthermore, there are large-scale experiments at JRC (EC JRC, 2014) to (i) assess the quality of social network data of 2010-2012 (by comparison with official data from EFFIS); (ii) map CS and Smart Cities projects; (iii) develop the typology of CS, set up facilities for social media data analysis and develop analytical tools; (iv) set up a framework for hosting citizen science project data (e.g. CitObs, EveryAware), websites and code after the end of project; (v) develop interoperability protocols and integration with official data sources (INSPIRE, Copernicus); (vi) develop partnerships with relevant stakeholders (e.g. ECSA, 2016); and (vii) explore the use of citizen-generated content to develop new indicators of quality of life in urban areas, with comparison to official sources (e.g. Eurobarometer).

\section{Citizen Science and Citizens' Observatories for Policy and Decision-Making}

The increasing numbers of CS activities and the rise of COs in recent years demonstrates one key fact: science needs public participation. We have already stated that the involvement of volunteers in the collection of observations and data can be beneficial for scientists who suffer from a constraint of resources. Another advantage that we inevitably come across is the fact that the participation of citizens in science will also serve the purpose of awareness raising, i.e. that people 
become more aware of problems or issues related to their direct environment and are consequently more likely to be in turn interested in the initiative and to be more willing to participate (Evans et al., 2005; Haklay, 2015). Several reviews of CS and CO projects indicate that the involvement of volunteers in science offers added value to science literacy and education effects (Kviner, 2012; Science Communication Unit, University of the West of England, 2013; Haklay, 2015; Grossberndt and Liu, 2016). A review of more than 230 "citizen science" projects concluded that volunteers have proven to provide information that has 'high value to research, policy, and practice' (Tweddle et al., 2012).

Although public participation has been given more attention in environmental governance processes recently, in most places it is still in its infancy. In 1998, the Aarhus Convention strengthened public participation through the establishment of 'the right to know', i.e., the access to environmental information, public participation in environmental decision-making and access to justice (UNECE, 1998). The EC Directive 2003/35/EC was adopted in 2003 to provide for public participation and thus implement the Aarhus Convention in the Member States of the EU (EC, 2003).

Involving citizens, and not only scientific experts, in environmental governance processes creates new opportunities. The EC published a White Paper in 2001 (EC, 2001), where they called upon different actors for cooperation within the whole process of environmental governance. The White Paper points to decisionmakers and scientists as actors of such governance, but also requests explicitly the inclusion of representatives from civil society. In 2014, the EU project Socientize developed a White Paper on Citizen Science for Europe (Socientize, 2012-2014), which aimed to support policy-makers at the European, national and regional levels to set up future strategies of civic engagement.

Both CS and COs can provide scientists with important and reliable data, enabling authorities to carry out informed policy-making, while providing citizens with opportunities to address issues affecting them at different scales. As citizens develop an increased scientific and environmental understanding, they may begin to influence decision-making and policy through activities such as petitions, public debate and advocacy, e.g., for identifying new policy issues, generating policy options, lobbying, supporting joined-up governance, etc. (Walters et al., 2000). An example of participatory monitoring impacting policy can be seen in Cambodia, where the Committee for Free and Fair Elections uses voter scorecards and volunteers with mobile phones to monitor if elected representatives keep their election promises. These examples have a direct impact on local policy and are the direct result of citizen participation and observation (Bottomley, 2014). However, many CS and CO programmes have yet to be evaluated for these impact attributes.

As addressed earlier in this chapter (see Section 1.2), the CO as a new concept that considers the wider implications of CS has evolved in EU policy circles. The existing and planned CO projects, and the results of their preliminary 
testing in practice, indicate that COs have a great potential to complement in-situ observation networks and to contribute to European policies covering areas from water management and air quality protection to biodiversity conservation.

In the 'Citizen Science and Policy: A European Perspective' report (Haklay, 2015), the following three policy dimensions are distinguished: (1) level of geography; (2) policy domains; and (3) level of engagement and type of CS activity. CS initiatives can influence policy decisions in a specific geographic area, i.e. local, regional, national or international. Usually, problems that affect the direct environment lead to more engagement, since people are more concerned (Haklay, 2015). This increased awareness can be leveraged to engage local people to contribute to CS initiatives. Local CS is often linked to environmental activism and supports community management by working towards effective and meaningful management planning and stewardship (Conrad and Hilchey, 2011). Local CS can also apply the so-called community-based monitoring $(\mathrm{CBM})$ approach. CBM describes a process where concerned citizens, public authorities and further stakeholders collaborate to monitor, track and respond to issues that arise from common community concerns (Whitelaw et al., 2003).

There is an increasing need for communities to fall back on CS approaches (or on CBM ones) and include different stakeholders with their diverse knowledge and experience into decision-making processes (Conrad and Daoust, 2008). In addition to potential savings in time and money for decision-making bodies, the societal benefits of CBM will be to create environmental democracy, social capital, and an increase in scientific literacy and inclusion in local issues (Conrad and Hilchey, 2011).

Policy areas can be manifold and partially overlapping. For example, cityscale policy includes public transport, environmental quality, education, infrastructure and public health. Thus, cities can be a canvas for a potpourri of local monitoring activities, originating from different concerns but using the accumulated data to see the bigger picture. Moving CS projects to the regional, national or even international level is likely to meet even more challenges than there already are. Since bottom-up initiatives usually dispose of limited budgets only, it will be less likely to find community science approaches with an active involvement of citizens in all parts of the participation cycle, i.e. citizens will instead only be asked to share observations or viewpoints on certain issues. Nevertheless, national and even international initiatives including CS are possible and do exist. Projects funded by the EC and formations of international organisations like the European Citizen Science Association ${ }^{14}$ provide frameworks for national initiatives and NGOs to create synergies to promote CS on larger scales and to call on international institutions such as the European Environment Agency (EEA) to promote citizen participation at the international level as well (Haklay, 2015). 
At present, there are still relatively few CS and CO examples that demonstrate where such projects have had a clear and distinct impact on both policy- and decision-making. However, this is dependent on how one perceives the 'level' of impact. Monitoring projects may not bring about immediate policy change, but their usefulness in building up evidence bases is invaluable. For example, the UK Biodiversity Indicators rely directly on the longterm data that NGOs and their volunteers collect for species such as birds and butterflies. These biodiversity indicators feed directly into wider UK and global policy, such as the Convention on Biological Diversity Strategic Plan for Biodiversity 2011-2020. Other projects that focus on observing and identifying invasive species, for example PlantTracker and the Harlequin Ladybird Survey, are valuable and will become increasingly relevant to policies in this area, such as the recently proposed EU Regulation on Invasive Alien Species and the developing of tree health policies within the UK (British Ecological Society, 2013).

Both CS and COs have an extremely important role to play in today's environmental science and research, and, through modern technology, innovative projects and new partnerships, the involvement of the public will only increase. The role of CS and CO projects in policy is relatively hard to gauge, but they are invaluable for building up evidence bases and directing change - especially those projects that are linked to some pressure groups (i.e. a group that tries to influence public policy in the interest of a particular cause) or that address environmental issues at the population level. Equally, given the educational values that citizen projects can provide, such projects may be influencing people's mindsets, which in turn could influence policy decisions in ways that are more abstract. As such, people really are power, not just for science but for policymaking too (British Ecological Society, 2013).

\section{Challenges and Development Needs}

As we have seen in this chapter so far, the idea of citizens participating in environmental governance is found not only in citizens' initiatives, but also at the international level, with e.g. the EU or UN as driving forces. However, there is still a discrepancy between theory and practice, owing to different circumstances and challenges. We shall now look a bit closer into the challenges that are connected to the implementation of CS and COs in environmental governance.

In this section, we distinguish between four different categories of challenges:

- Technologies and data;

- Citizen engagement;

- Policies and framework;

- Additional requirements for COs. 


\subsection{Technologies and Data}

CS approaches and COs require strict data management. In both cases, volunteers who do not necessarily possess the required skills for the collection process can still gather large amounts of data; however, the obtained data often contain errors and bias. It takes time and resources to train the volunteers to enable them to collect data in the manner and of a quality that is useful for scientists, decision-makers and other stakeholders (Conrad and Hilchey, 2011; Dickinson et al., 2010; Engelken-Jorge et al., 2014; Goodchild and Li, 2012; Hanahan and Cottrill, 2004). An insufficient experimental design can hence lead to undesired outcomes (Conrad and Hilchey, 2011). Another requirement is the management and analysis of the continuously increasing volume, variety and velocity of the data that are collected throughout the whole course of the initiative (Zikopoulos et al., 2011). One option to deal with this issue is to build networks with other existing projects or initiatives to use already existing datasets and combine them with newly obtained data (Dickinson et al., 2010). However, special attention must be paid to accuracy and uncertainty, especially when comparing crowdsourced with referenced data. The same applies for the interpretation of qualitative data; indicators such as 'quality of life' or 'wellbeing' should be developed together with more quantitative data. In addition, data security and privacy are important issues that require special attention. Especially when using smartphones and/or mobile sensing devices, it has to be ensured that the data from the volunteers are anonymised and treated according to national and international data protection laws and standards. In addition, ethical restrictions may apply (Liu et al., 2014). Increasing the amount of data requires progressive technologies and data analysis methods that reduce measurement uncertainties through real-time, reliable and fast quality assurance/quality control tools. Furthermore, there is an urgent need to explore and develop technologies for data collection and analysis by building the technical capacity required to combine environmental monitoring with the exchange and integration of different types of data, then visualise and communicate the results to end users (Liu et al., 2014; DFID, 2008).

The evaluation of citizen science and especially of CO approaches is another topic that requires further research. Indicators for evaluation and value proposition have to be developed to facilitate the comparison of initiatives from different fields and their effectiveness/efficiency, especially regarding engagement and participation.

\subsection{Citizen Engagement}

Engaging with volunteers to participate in any form of activity related to CS or COs can be quite challenging. The most crucial task is to raise the interest of the volunteers to actively participate and continue until the end of the initiative. 
If there is no interest, there will be no data. In addition, few people will spend their spare time and resources for nothing; the volunteers must clearly know what to expect in return, i.e. what is in it for them. Thus, it is essential to implement various tailor-made tools to recruit and sustain citizen participation in environmental monitoring activities (Fernandez-Gimenez et al., 2008; Conrad and Hilchey, 2011). One of the preconditions for successful involvement of volunteers in CS activities is their level of interest in the research itself. Nevertheless, many volunteers seem to contribute very little at the beginning of data collection activities, leaving a rather small amount of volunteers contributing the most (Sauermann and Franzoni, 2015). Thus, keeping the volunteers' interest through fun activities seems to bear potential for a higher contribution rate. So-called 'gamification' for this purpose seems to show positive results; however, this is very much dependent on the project type and the volunteers and requires further research (Prestopnik et al., 2014). Immediate and continuous feedback of results in a visually attractive and easy to understand manner is also important. Social media can also be a good way to keep in contact with the volunteers (Gottschalk Druschke and Seltzer, 2012). Furthermore, it is very helpful to engage and to retain citizens by clearly addressing the positive aspects of their participation, for example the benefits they can gain, such as improved health, knowing which areas are polluted and how to avoid exposure (in the case of air quality) or personal recognition (e.g. through a leader board in the community). Being able to access data from other volunteers and to compare them to the data collected by oneself, as well as dashboard and analytical tools accessible to the volunteers, etc., are all useful methods to engage citizens.

\subsection{Policies and Framework}

Even though participative approaches in environmental governance have been repeatedly promoted at an international level, this does not mean that these approaches are automatically followed up at national, regional or local levels. Next to the obvious willingness of decision-makers, their level of readiness is a crucial precondition for success. In this context, funding opportunities play an important role (Conrad and Hilchey, 2011; Litke and Day, 1998). CS and COs represent powerful and usually low-cost solutions to address existing gaps in environmental governance. These platforms can allow authorities to obtain evidence and provide citizens with opportunities to address environmental concerns. However, often, citizens participating in environmental governance are considered a 'threat' rather than a resource to decision-makers, since they are deemed to be in opposition to the plans of the authorities or industries. Citizen participation should rather be considered as a means to make environmental governance more transparent so that the citizens' trust in the conclusions of experts will increase. Here, the challenge lies in integrating CS in environmental 
decision-making in a manner that enhances the process by enabling it to deal with issues concerning the community appropriately and that at the same time takes into consideration the risks and opportunities that go along with these practices (Hakley, 2015).

\subsection{Additional Requirements for Citizens' Observatories}

Additionally to the challenges that have been mentioned so far, the establishment of COs is accompanied by a number of further development needs. COs usually have a similar structure; however, when starting a new $\mathrm{CO}$, the whole infrastructure and data flow have to be installed from scratch (Liu et al., 2014). So far, there are no systematic, easy and reusable methods to do so. This causes an unsurmountable hurdle for institutions and organisations, as they usually lack the specific technical ICT and programming knowledge to create the required server infrastructure and mobile applications. As a result, organisations can fall back on old-fashioned, non-technological methods (which can take longer to implement) or spend tremendous amounts of their often limited budget on external ICT and programming experts (D'Hondt et al., 2014; Zaman et al., 2014).

Liu et al. (2014) have identified the following development needs to ensure a functional and operational $\mathrm{CO}$ with the active involvement of citizens:

A. The adequate promotion of a $\mathrm{CO}$ platform, including tools and activities for capacity building, awareness raising, recruiting and maintaining the participation of citizens;

B. A good understanding of the current and future societal demography in order to create COs that meet the actual and future needs of the population;

C. Building a long-lasting infrastructure, including open source software with the following requirements: use of open standards, easy exploitation through an open Application Programming Interface (API), and the ability to be widely accessed, extended and maintained. A CO should be seen rather as a generic environmental enabler than as a project-specific outcome;

D. Addressing and evaluating both citizens' views on certain environmental issues and their related actions ('Citizens' Voice') and the accountability of the governments for their environmental actions ('Accountability') in the social and political context of each CO (Fernandez-Gimenez et al., 2008). These two concepts should be actively promoted as important dimensions of good environmental governance, and that also in relation to the improvement of social justice (DFID, 2008; Kamar et al., 2012);

E. Developing tailor-made channels and mechanisms to enable citizens to actually influence environmental governance processes. 


\section{Conclusions}

Engaging citizens in science and environmental observations is a challenging task. While many scientists are cautious about using data from volunteered observations, others believe that the quality of such data is sufficient to allow them to either use or publish the data while admitting that further work may be required before applying such data in other ways. However, we cannot say much about the quality of data from COs, as further research is still needed. The need for further research also applies to the validation processes, data integration and quality management. Merging citizen data with authoritative data and integration with other existing data may also be considered. Another way to improve data quality is to pay attention to the composition of the volunteer groups. In order to avoid imbalances and biases in the observations, the volunteers should be representative of different groups (e.g. different age, gender or cultural background groups, etc.). Applying co-design approaches in the design of the study/initiative can also be a useful way to maximise outputs of the observation process.

In order for citizens to participate in CS and CO initiatives, we have to create activities with low barriers and with incentives for citizens to both start participating and continue to do so. To succeed, we (the scientists) have to respect every volunteer and the role they play, manage their expectations and be transparent in our plans and actions. In addition, we must ensure to protect private data and create secure solutions. To the same degree, we have to respect and deal with the expectations, concerns and fears of public authorities in the same open and transparent manner. It is important to include and engage public authorities, where applicable, from the start to increase the chances of sustainable outcomes and solutions, and to influence their policies.

More can be done to promote citizen participation in environmental governance. With its latest Framework Programme for Research and Innovation, Horizon 2020, the EC is strongly promoting citizen engagement. Aiming to deepen the relationship between science and society and to reinforce public confidence in science, Horizon 2020 should foster the informed engagement of citizens and civil society in research and innovation by promoting science education, making scientific knowledge more accessible and developing responsible research, as well as innovation agendas that meet the actual concerns and expectations of citizens. In order to facilitate the participation of citizens in Horizon 2020, the engagement of citizens and civil society should be coupled with public outreach activities to generate and sustain public support for Horizon 2020 and beyond. Furthermore, EU research in this area often consists of top-down prescribed CO and CS programmes, which would need to be compatible with the existing bottom-up networks and the true data needs of citizens. Together, these top-down and bottom-up approaches allow us to mini- 
mise the differences and maximise the similarities among multiple systems, enabling both individual-case-study data analysis and integrated data analysis to be performed (Liu et al., 2014).

The growth in Web-based CS and COs and the use of mobile phones have opened many new opportunities for instrumental observations that can enhance the abilities of analysts to use this information for decision-making processes. Overall, policy-makers and government officials need to be aware that CS and COs, in the latter's new incarnation, are a phenomenon that will continue to grow and impact all levels of government. Each CS and CO activity will always involve trade-offs between inclusion of people, education, awareness of science and contribution to scientific research; the emerging examples from Europe show that, with appropriate multidisciplinary teams, it is possible, however, to achieve several of these goals in any given activity.

Another opportunity within COs is the potential for social innovation, novel partnerships and creating new opportunities for SMEs. This would meet the need for more cross-cutting and transdisciplinary activities that again would result in the creation of synergies and the facilitation of interoperability and coordination.

Whereas CS initiatives have had the chance to learn and undergo different changes through the course of the last decades, the concept of CO is rather young. Initiatives following this approach are still at an early stage and an honest discussion about their risks and opportunities needs to be carried out with citizens, scientists, authorities and other potential stakeholders in order to determine the full potential and areas of application of COs; only the future will show if our efforts were worth it.

\section{Acknowledgements}

The ideas presented here evolved from work undertaken in the context of studies funded under the CITI-SENSE and hackAIR projects. CITI-SENSE was a collaborative project partly funded by the EU FP7-ENV-2012 under Grant Agreement No. 308524. hackAIR is supported through the EU programme on 'Collective Awareness Platforms for Sustainability and Social Innovation' and funded through the Horizon 2020 Research and Innovation Programme under Grant Agreement No. 688363. We would like to thank, Steffen Fritz, the referee for this chapter, for his very valuable comments.

\section{Previous publication}

Figures 1 and 3 in this chapter have been modified from the following work: Citizen Participation Approaches in Environmental Health. In: Jozef M. Pacyna 
and Elisabeth G. Pacyna (eds.) Environmental Determinants of Human Health 2016, pp. 225-248, Sonja Grossberndt and Hai-Ying Liu.

(C) Springer International Publishing Switzerland 2016

This work is subject to copyright. All rights are reserved by the Publisher, whether the whole or part of the material is concerned, specifically the rights of translation, reprinting, reuse of illustrations, recitation, broadcasting, reproduction on microfilms or in any other physical way, and transmission or information storage and retrieval, electronic adaptation, computer software, or by similar or dissimilar methodology now known or hereafter developed.

The use of general descriptive names, registered names, trademarks, service marks, etc. in this publication does not imply, even in the absence of a specific statement, that such names are exempt from the relevant protective laws and regulations and therefore free for general use.

The publisher, the authors and the editors are safe to assume that the advice and information in this book are believed to be true and accurate at the date of publication. Neither the publisher nor the authors or the editors give a warranty, express or implied, with respect to the material contained herein or for any errors or omissions that may have been made. "With permission of Springer"

\section{Notes}

${ }^{1}$ http://citizen-obs.eu/

${ }^{2}$ http://gbbc.birdcount.org/

${ }^{3}$ http://www.bigbutterflycount.org/

${ }^{4}$ http://www.openstreetmap.org

${ }^{5}$ http://airqualityegg.com/

${ }^{6} \mathrm{http}: / /$ www.opalexplorenature.org/aboutOPAL and http://www.imperial. ac.uk/opal/

${ }^{7}$ http://www.geo-wiki.org

${ }^{8}$ https://www.zooniverse.org/

${ }^{9}$ http://vgibox.eu/

${ }^{10}$ http://cartography.tuwien.ac.at/emomap/

${ }^{11}$ http://www.everyaware.eu/

${ }^{12}$ http://www.citizencyberscience.net/

${ }^{13} \mathrm{http}: / /$ www.opalexplorenature.org/aboutOPAL and http://www.imperial. ac.uk/opal/

${ }^{14}$ https://ecsa.citizen-science.net/

\section{Reference list}

Bonney, R., Ballard, H., Jordan, R., McCallie, E., Phillips, T., Shirk, J., Wilderman, C. C., 2009. Public Participation in Scientific Research: Defining the 
Field and Assessing Its Potential for Informal Science Education. A CAISE Inquiry Group Report. Washington, D.C.: Centre for Advancement of Informal Science Education (CAISE).

Bottomley, R., 2014. The Role of Civil Society in Influencing Policy and Practice in Cambodia: Report for Oxfam Novib. Available at https://www. worldcitizenspanel.com/assets/The-Role-of-Civil-Society-in-InfluencingPolicy-and-Practice-in-Cambodia.pdf [Last accessed 16 December 2016].

Brenna, B., 2011. Clergymen Abiding in the Fields: The Making of the Naturalist Observer in Eighteenth-Century Norwegian Natural History. Science in Context 24(2): 143-166.

British Ecological Society, 2013. Is there a role for the citizen scientist in policy making? Available at http://www.britishecologicalsociety.org/ blog/2013/12/11/is-there-a-role-for-the-citizen-scientist-in-policy-making/ [Last_accessed 30 May 2016].

Ceccaroni, L., Velickovski, F., Blaas, M., Wernand, M.R., Blauw, A., Subirats, L., 2016. Citclops Data Explorer: exploring water quality in the Wadden Sea, in: Berre, A.J., Schade, S., Piera, J. (Eds.) Proceedings of the Workshop "Environmental Infrastructures and Platforms 2015 - Infrastructures and Platforms for Environmental Crowd Sensing and Big Data", co-located with the European Citizen Science Association General Assembly 2015 (ECSA GA'2015). Barcelona, Spain, October 28-30 October, 2015.

Ciravegna, F., Huwald, H., Lanfranchi, V., Wehn de Montalvo, U., 2013. Citizen observatories: the WeSenseIt Vision, in: Proceeding of the Infrastructure for Spatial Information in the European Community (INSPIRE 2013). Florence, Italy, 23-27 June, 2013, 1-2.

Citclops, 2012-2015. Citizens' observatory for coast and ocean optical monitoring. Available at http://www.citclops.eu. [Last accessed 20 October 2015].

CITI-SENSE, 2012-2016. Development of sensor-based citizens' observatory community for improving quality of life in cities. Available at http://www. citi-sense.eu [Last accessed 20 October 2015].

COBWEB, 2012-2016. Citizen Observatory web. Available at http://cobwebproject.eu [Last accessed 20 October 2015].

Conrad, C.C., Hilchey, K.G., 2011. A review of citizen science and communitybased environmental monitoring: issues and opportunities. Environmental Monitoring and Assessment 176: 273-291.

Conrad, C.T., Daoust, T., 2008. Community-based monitoring frameworks: increasing the effectiveness of environmental stewardship. Environmental Management 41: 358-366.

Department for International Development (DFID), 2008. Citizens' voice and accountability evaluation. Mozambique country case study (final report). Evaluation report EV688. Available at https://www.gov.uk/government/ publications/citizens-voice-and-accountability-evaluation-mozambiquecountry-case-study-final-report-ev688 [Last accessed 1 May 2017]. 
D’Hondt, E., Zaman, J., Philips, E., Gonzalez Boix, E., De Meuter, W., 2014. Orchestration Support for Participatory Sensing Campaigns, in: Proceedings of the 2014 ACM International Joint Conference on Pervasive and Ubiquitous Computing (UbiComp 2014). ACM, New York, USA, 13 September, 2014, pp., 727-738.

Dickinson, J.L., Zuckerberg, B., Bonter, D.N., 2010. Citizen Science as an Ecological Research Tool: Challenges and Benefits. Annual Review of Ecology, Evolution, and Systematics 41: 149-172.

EC (European Commission), 2001. European Governance - A White paper. 2001/C 287/01. Available at http://europa.eu/rapid/press-release_DOC-0110_en.htm [Last accessed 1 May 2017].

EC (European Commission), 2003. Directive 2003/35/EC of the European Parliament and of the Council providing for public participation in respect of the drawing up of certain plans and programmes relating to the environment and amending with regard to public participation and access to justice Council Directives 85/337/EEC and 96/61/EC. Available at http:// eur-lex.europa.eu/resource.html?uri=cellar:4a80a6c9-cdb3-4e27-a721d5df1a0535bc.0004.02/DOC_1\&format=PDF [Last accessed 1 May 2017].

EC (European Commission), 2014. CORDIS - Programmes: Developing community-based environmental monitoring and information systems using innovative and novel earth observation applications. Available at http://cordis.europa.eu/programme/rcn/18152_en.html [Last accessed 10 May 2016].

EC (European Commission), 2015. What is MYGEOSS. Available at http:// digitalearthlab.jrc.ec.europa.eu/mygeoss/ [Last accessed 12 May 2016].

EC (European Commission), 2015-2016. TOPIC - Demonstrating the concept of 'Citizen Observatories'. Available at https://ec.europa.eu/research/participants/portal/desktop/en/opportunities/h2020/topics/sc5-17-2015.html [Last accessed 12 May 2016].

EC (European Commission), 2016. CAPS projects. Available at https://ec.europa. eu/digital-single-market/node/66639 [Last accessed 12 May 2016].

EC (European Commission), 2016-2017a. TOPIC - Novel in-situ observation systems. Available at http://ec.europa.eu/research/participants/portal/ desktop/en/opportunities/h2020/topics/sc5-18-2017.html [Last accessed 12 May 2016].

EC (European Commission), 2016-2017b. TOPIC - Coordination of citizens' observatories initiatives. Available at http://ec.europa.eu/research/participants/portal/desktop/en/opportunities/h2020/topics/sc5-19-2017.html [Last accessed 12 May 2016].

EC (European Commission), 2016-2017c. TOPIC - Collective Awareness Platforms for Sustainability and Social Innovation. Available at http:// ec.europa.eu/research/participants/portal/desktop/en/opportunities/ h2020/topics/5070-ict-11-2017.html [Last accessed 12 May 2016]. 
EC (European Commission), 2017. TOPIC - Integrating Society in Science and Innovation - An approach to co-creation. Available at http://ec.europa. eu/research/participants/portal/desktop/en/opportunities/h2020/ topics/2264-swafs-13-2017.html [Last accessed 12 May 2016].

EC JRC (European Commission Joint Research Centre), 2014. Citizen Science and Smart Cities. Available at http://publications.jrc.ec.europa.eu/repository/bitstream/JRC90374/lbna26652enn.pdf [Last accessed 12 May 2016].

Engelken-Jorge, M., Moreno, J., Keune, H., Verheyden, W., Bartonova, A., 2014. CITISENSE consortium: Developing citizens' observatories for environmental monitoring and citizen empowerment: challenges and future scenarios, in: Parycek P, Edelmann N. (eds.) Proceedings of the Conference for E-Democracy and Open Government (CeDEM14). Danube University Krems, Austria 21-23 May 2014, 49-60.

European Citizen Science Association (ECSA), 2016. Available at http://ecsa. citizen-science.net/ [Last accessed 12 May 2016].

Evans, C., Abrams, E., Reitsma, R., Roux, K., Salmonsen, L., Marra, P.P., 2005. The neighborhood nestwatch program: participant outcomes of a citizenscience ecological research project. Conservation Biology 19:589-594.

Fernandez-Gimenez, M.E., Ballard, H.L., Sturtevant, V.E., 2008. Adaptive management and social learning in collaborative and community-based monitoring: a study of five community-based forestry organizations in the western USA. Ecology and Society 13:4.

Feyerabend, P.K., 1970. Against method: online of an anarchistic theory of knowledge. Minnesota Studies in the Philosophy of Science 4:17-130.

Goodchild, M.F., Li, L., 2012. Assuring the quality of volunteered geographic information. Spatial Statistics 1:110-120.

Gottschalk Druschke, C., Seltzer, C.E., 2012. Failures of Engagement: Lessons Learned from a Citizen Science Pilot Study. Applied Environmental Education \& Communication 11(3-4): 178-188. DOI: https://doi.org/10.1080/15 33015X.2012.777224.

Grossberndt, S., Liu, H.-Y., 2016. Citizen participation approaches in environmental health. In Pacyna, J., Pacyna, E. (Eds.), Environmental Determinants of Human Health. London, UK: Springer, pp. 225-248.

Haklay, M., 2015. Citizen science and policy: a European perspective. Washington, DC: Woodrow Wilson International Centre for Scholars.

Hanahan, R.A., Cottrill, C., 2004. A comparative analysis of water quality monitoring programs in the southeast: lessons for Tennessee. Available at http:// isse.utk.edu/wrrc/programsprojects/pdfs/mainbook.pdf [Last accessed 12 May 2016].

Higgins, C.I., Williams, J., Leibovici, D.G., Simonis, I., Davis, M.G., Muldoon, C., O'Grady, M., 2016. Generic Infrastructure Platform to Facilitate the Collection of Citizen Science data for Environmental Monitoring. International Journal of Spatial Data Infrastructures Research 11, 20-48. 
Kamar, E., Hacker, S., Horvitz, E., 2012. Combining human and machine intelligence in large-scale crowdsourcing, in: Proceedings of the 11th International Conference on Autonomous Agents and Multiagent Systems (AAMAS 2012). Valencia, Spain, 4-8 June 2012, pp. 467-474.

Kullenberg, C., Kasperowski, D., 2016. What Is Citizen Science? - A Scientometric Meta-Analysis. PLoS ONE 11(1): e014. 7152. DOI: https://doi. org/10.1371/journal.pone.0147152.

Kviner, M., 2012. Review highlights role of citizen science projects. Available at http://www.bbc.com/news/science-environment-20445296 [Last accessed 12 May 2016].

Lanfranchi, V., Wrigley, S.N., Ireson, N., Ciravegna, F., Wehn, U., 2013. Citizens' observatories for situation awareness in flooding, in: Hiltz, S.R., Pfaff, M.S., Plotnick, L., Shih, P.C. (Eds.) Proceedings of the 11th International ISCRAM Conference. University Park, Pennsylvania, USA, 19-22 May 2014, pp. 145-154. Available at: http://www.iscram.org/legacy/ISCRAM2014/ papers/p40.pdf [Last accessed 16 May 2017].

LeBaron, G.S., 2015. The $115^{\text {th }}$ Christmas bird count. Available at https://www. audubon.org/news/the-115th-christmas-bird-count-0 [Last accessed 12 May 2016].

Litke, S., Day, J.S., 1998. Building local capacity for stewardship and sustainability: the role of community-based watershed management in Chilliwack, British Colombia. Environments 25: 91-110.

Liu, H-Y., Kobernus, M., 2017. Citizen science and its role in the sustainable development. In Ceccaroni, L., Piera, J. (Eds.), Analysing the Role of Citizen Science in Modern Research. Advances in Knowledge Acquisition, Transfer, and Management. Hershy, PA, USA: IGI Global, pp. 147-167.

Liu, H-Y., Kobernus, M., Broday, D., Bartonova, A., 2014. A conceptual approach to a citizens' observatory - supporting community-based environmental governance. Environmental Health 13:107.

Miller-Rushing, A., Primack, R., Bonney, R., 2012. The history of public participation in ecological research. Frontiers in Ecology and the Environment 10(06):285-290, DOI: https://doi.org/10.1890/110278.

Omniscientis, 2012-2014. Odour monitoring and information system based on citizen and technology innovative sensors. Available at http://www. omniscientis.eu/ [Last accessed 1 May 2017].

Oxford English Dictionary (OED), 2014. Third Edition. Available at http:// www.oed.com/view/Entry/33513?redirectedFrom=citizen+science\# eid316619123 [Last accessed 12 May 2016].

Prestopnik, N., Crowston, K., Wang, J., 2014. Exploring Data Quality in Games with a Purpose, in: Proceedings of the iConference 2014, Berlin, Germany, 4-7 March 2014, pp. 213-228. DOI: https://doi.org/10.9776/14066. Available at: https://www.ideals.illinois.edu/bitstream/handle/2142/47311/066_ ready.pdf? sequence=2\&isAllowed=y [Last accessed 12 May 2017]. 
Sauermann, H., Franzoni, C., 2015. Crowd science user contribution patterns and their implications. PNAS 2015112 (3) 679-684; published ahead of print January 5, 2015, DOI: https://doi.org/10.1073/pnas.1408907112.

Science Communication Unit, University of the West of England, Bristol, 2013. Science for Environment Policy In-depth Report: Environmental Citizen Science. Report produced for the European Commission DG Environment, December 2013. Available at: http://ec.europa.eu/science-environmentpolicy [Last accessed 12 May 2016].

SciStarter, 2017. https://scistarter.com/about. [Last accessed 04 July 2017].

Shirk, J. L., Ballard, H. L., Wilderman, C. C.,Phillips, T., Wiggins, A., Jordan, R., McCallie, E., Minarchek, M., Lewenstein, B. V.,Krasny, M. E., Bonney, R., 2012. Public participation in scientific research: a framework for deliberate design. Ecology and Society 17(2): 29. http://dx.doi.org/10.5751/ES-04705170229. Accessed 16 December 2016.

Silvertown, J., 2009. A new dawn for citizen science. Trends in Ecology \& Evolution 24 (9): $467-471$.

Socientize, 2012-2014. Society as e-Infrastructure through technology, innovation and creativity. Available at http://www.socientize.eu/ [Last accessed 12 May 2016].

Tulloch, A.I.T., Possingham, H.P., Joseph, L.N., Szabo, J., Martin, T.G., 2013. Realising the full potential of citizen science monitoring programs. Biological Conservation 165:128-138.

Tweddle, J. C., Robinson L. D., Pocock, M. J., Roy, H. E., 2012. Guide to citizen science: developing, implementing and evaluating citizen science to study biodiversity and the environment in the UK. Natural History Museum and Centre for Ecology and Hydrology.

United Nations Economic Commission for Europe (UNECE), 1998. Convention on Access to Information, Public Participation in Decision-Making and Access to Justice in Environmental Matters. Available from: https:// www.unece.org/fileadmin/DAM/env/pp/documents/cep43e.pdf [Last accessed 16 May 2017].

University of the West of England (UWE), 2014. Science for Environment Policy In-depth Report: Environmental Citizen Science. Report produced for the European Commission DG Environment, February 2014. Available at: http://ec.europa.eu/environment/integration/research/newsalert/pdf/ IR10_en.pdf [Last accessed 12 May 2016].

University of the West of England (UWE), 2013. Science for Environment Policy In-depth Report: Environmental Citizen Science. Report produced for the European Commission DG Environment, December 2013. Available at: http://ec.europa.eu/science-environment-policy [Last accessed 12 May 2016].

Vetter, J., 2011. Lay observers, telegraph lines, and Kansas weather: the field network as a mode of knowledge production. Science in Context 24:259-280. 
Walters, L.C., Aydelotte, J., Miller, J., 2000. Putting more public in policy analysis. Public Administration Review 60(4):349-359.

Wehn, U., Evers, J., 2015. The social innovation potential of ICT-enabled citizen observatories to in-crease eParticipation in local food risk management. Technology in Science 2015 42: 187-198.

WeSenseIt, 2012-2016. Citizen water observatories. Available at http://www. wesenseit.com [Last accessed 20 October 2015].

Whitelaw, G., Vaughan, H., Craig, B., Atkinson, B., 2003. Establishing the Canadian community monitoring network. Environmental Monitoring and Assessment 88:409-418.

Zaman, J., D’Hondt, E., Gonzalez Boix, E., Philips, E., Kambona, K., De Meuter, W., 2014. Citizen-Friendly Participatory Campaign Support, in: Proceedings of 2014 IEEE International Conference on Pervasive Computing and Communications Work in Progress (PerCom WiP'14). Budapest, Hungary, 24-28 March, 2014, Pages 232 - 235.

Zikopoulos, I.B.M.P., Eaton, C., Zikopoulos, P., 2011. Understanding Big Data: Analytics for Enterprise Class Hadoop and Streaming Data. McGraw-Hill Professional, New York, USA.

Zooniverse, 2013. Purpose. Zooniverse. Available at http://www.zooniverse. org/about [Last accessed 1 May 2017]. 